\title{
Sclerosing angiomatoid nodular transformation (SANT): A rare entity of spleen
}

\author{
Mehmet Yildirim $^{1 *}$, Oktay Bilgir ${ }^{2}$, EnverVardar ${ }^{3}$ and Selin Canpolat ${ }^{3}$ \\ ${ }^{1}$ University of Health Sciences, Bozyaka Education and Research Hospital, Departmant of General Surgery, Izmir, Turkey \\ ${ }^{2}$ University of Health Sciences, Bozyaka Education and Research Hospital, Departmant of Heamatology, Izmir,Turkey \\ ${ }^{3}$ University of Health Sciences, Bozyaka Education and Research Hospital, Departmant of Pathology, Izmir,Turkey
}

\begin{abstract}
Sclerosing angiomatoid nodular transformation(SANT) is benign neoplasm originating from vascular cells of the spleen. These tumors are rare between splenic lesions. In this paper,we present a SANT that arose in the upper pole of the spleen of a 61-years-old female. During the examination for anemia and diabetes mellitus,an splenic mass was found incidentally at the CT imaging. Open laparotomy with splenectomy was performed.Histopathological features of this tumor confirmed a rich vascular network in the nodule surrended by hyalin cortex. In this report, we discuss the differential diagnosis of SANT.
\end{abstract}

\section{Introduction}

Sclerosing angiomatoid nodular transformation (SANT) is uncommon disorder characterized by benign proliferation of vasculer tissue in the splenic red pulpa and was first described by Martel, et al. in 2004 [1]. In the report, they were described 25 cases with angiomatoid nodules surrounded by dense fibrous tissue. About since than 132 cases of SANT have been reported in the English literature [2]. SANT usually presents as a splenic tumoral mass, but it rarely manifests clinically symptoms.

A retrospective review of the surgical database was performed to identified SANT at our institution from January 2010 to January 2016. We found only one SANT of spleen between 117 splenectomy specimens. In this paper, a patient who attended hospital with anemia and diabetes mellitus and by incidentally were found to have SANT on splenectomy specimen is presented.

\section{Case report}

A 61-year-old female with a history of chronic pulmonary symptoms and anemia was admitted to Depertmant of Internal Medicine in our hospital for further investigation. A physical examination revaled the patient to be afebrile and no abnormalities other than the vaguely tenderness in the left upper quadrant. She had been suffering from diabetic retinopathy for 3 years. Laboratory examinations revealed hemoglobine $10.6 \mathrm{~g} \backslash \mathrm{dl}$, hematocrite $35 \%$, BCR-ABL transcript(-) and JAK-2 (-), while the chest X-ray findings and liver function were normal. Ultrasound of the abdomen was incoclusive. CT imaging showed a 3 $\mathrm{cm}$ tumoral mass at the upper pole of spleen (Figure1). The patient was admitted to our Surgery Department. The tumor was suspected to be a splenic lymphoma or a another type of malignanat lymphoma. A laparotomy was performed,which revealed a tumoral mass on the spleen. The patient underwent a splenectomy. The postoperative course was eneventful.

The splenic tumor was visiable and yellowish-white noduler, irreguler tumoral mass in the upper pole (Figure 2). The resected spleen weighed $204 \mathrm{gm}$ and the tumor size was $2.5 \times 2.8 \times 2.5 \mathrm{~cm}$. Histologically the mass showed hyalin capsule formation around the noduler lesion with increased vascularity. Immunohistologic studies showed, CD $34(+)$ cells in capilleries, CD31(+) cells in capilleries, sinusoids and small venules, Factor $8(+)$, vimentin(+), smooth muscle actin $(+)$, S100(+), Desmin(-) cells in capilleries and sinusoids, and usual staining cells with CD3, CD15, CD20, CD30, CD38, PAX5 and Ki67. The final pathological diagnosis was SANT of the spleen.

\section{Discussion}

Primary splenic vascular neoplasms arise from the red pulp of the spleen. Previously, these lesions were called as hamartomas, hemangioendoteliomas, sclerosed hamangiomas capiller hemangioma,

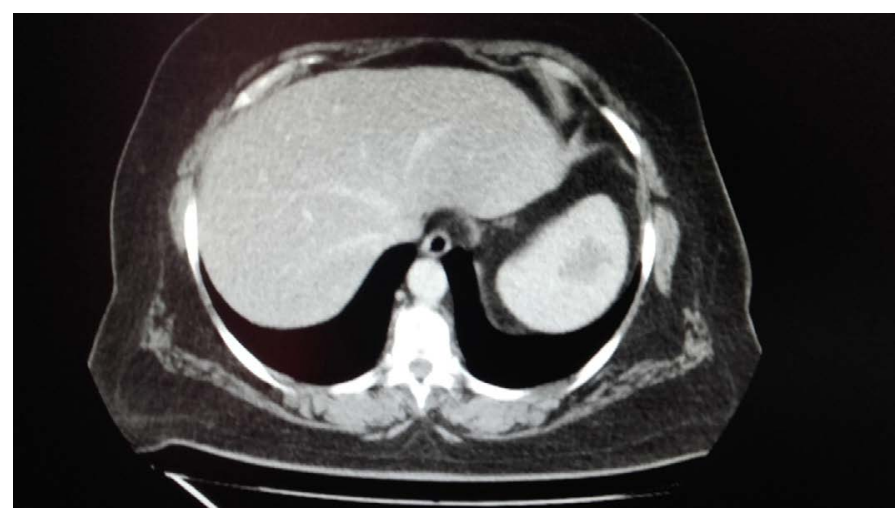

Figure 1. CT image of the patient shows an intrasplenic mass.

Correspondence to: Dr. Mehmet Yildirim, University of Health Sciences, Bozyaka Education and Research Hospital, Departmant of General Surgery, Izmir, Turkey, Tel. 090532 2855557; E-mail:mehmetyildi@gmail.com

Key words: sclerosed, angiomatoid, noduler transformation

Received: August 07, 2017; Accepted: August 19, 2017; Published: August 22, 2017 


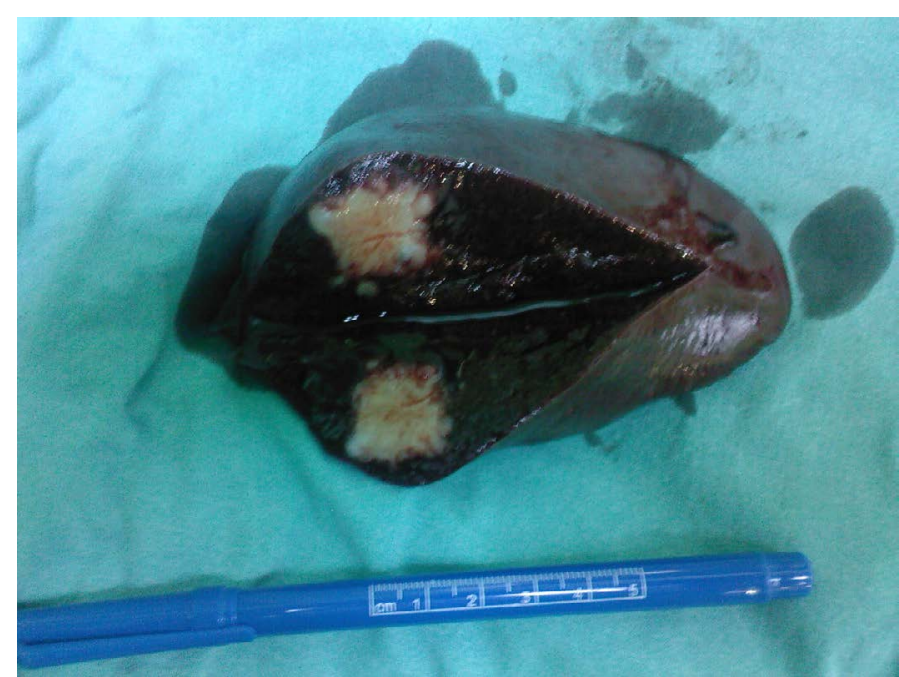

Figure 2. Macroscopy of the excised tumor demonstrates irreguler mass with a yellowishwhite cut surface showing noduler pattern.

multinoduler hemangioma, and inflammatory pseudotumors. Currently,they classified as sclerosing angiomatoid nodular transformation (SANT) of spleen. Although clinical significance of SANT is unclear,they are important lesions because they may be confused with malign tumors [3]. Furthermore, some papers reported that SANT showed a relationship with systemic inflammatory reaction, Epstein-Barr virus infection, trauma and splenic hematomas. Our case showed no evidence of primary etiologic reason.

The majority of SANT is asymptomatic and discovered incidentally during imaging studies as in our case,or they can present with symptoms related to tumor compression of adjacent organs. Patients presenting with symptoms generally complain of abdominal pain,abdominal distansion or a palpabl mass [4]. Generally, age of onset is in the fifth decade, but it might observed from second to seventh decade.

On sonography SANT appears as a hypoechoic mass with linear echoes that is suspicious for malignancy. CT is the best imaging technique for evaluating tumor extent. It seems that the presence of the radiating septations in the nodule, spoke-wheel sign, might be diagnostic for SANT. Despite the various diagnostic modalities, SANT remains difficult to distinguish preoperatively from a tumor. Some authors reported that fine needle biopsy of the lesion is a good method for diagnosis but this method carries the risk of dissemination of a malign neoplasm.

Histologically SANT of the spleen are composed by angiomatoid nodules with infiltrative stromal process. Immunohistochemistry is very important for the diagnostic confirmation. SANT have been categorized three types.Type 1 contains well formed capilleries with CD34(+),CD8 (-),CD31(+), Type 2 includes vessels similar splenic sinusoids with pattern CD34(-),CD8 (+),CD31(+).Type 3 covers mesh-like patterns of small veins with CD34(-),CD8 (-),CD31(+).(3) In our case, histologically, the appearances of angimatoid nodules and vascular staining with CD34 and C31 benefited differention from hemangiomas, Littoral cell angioma, hamartoma and angiosarcomas.

SANT is still poorly understood,and its diagnosis represents for the lack of specific diagnostic methods as well as biochemical and biological markers. Making a correct diagnosis was very difficult before the operation. Because SANT may be confused with malignanat lesions, recommended treatment is splenectomy.

\section{References}

1. Martel M, Cheuk W, Lombardi L, Lifschitz-Mercer B, Chan JK, Rosai J (2004) Sclerosing angiomatoid nodular transformation (SANT): Report of 25 cases of a distinctive benign splenic lesion. Am J Surg Pathol 28: 1268-1279. [Crossref]

2. Wang TB, Hu BG, Liu DW, Gao ZH, Shi HP, Dong WG (2016) Sclerosing angiomatoid nodular transformation of the spleen: A case report and literature review. Oncology Letters 12: 928-932.

3. Agrawal M, Uppin SG, Srinivas BH, Uppin MS, Bheerappa N, Challa S (2016) Sclerosing angiomatoid nodular transformation of the spleen:A new entitiy or a new name? Türk Patoloji Derg 32: 205-210. [Crossref]

4. Falk GA, Nooli NP, Morris-Stiff G, Plesec TP, Rosenblatt S (2012) Sclerosing angiomatoid nodular transformation (SANT) of the spleen:case report and review of the literature. Int J Surg Case Rep 3: 492-500. [Crossref]

Copyright: (C2017 Yildirim M. This is an open-access article distributed under the terms of the Creative Commons Attribution License, which permits unrestricted use, distribution, and reproduction in any medium, provided the original author and source are credited. 